\title{
Israel Sanmartín Barros, Patricia Calvo González y Eduardo Rey Tristán (eds.), Historia(s), Imágen(es) y Lenguaje(s) en América Latina y Europa. Santiago de Compostela: Universidade de Santiago de Compostela, Servizo de Publicacións e Intercambio Científico, 2012, 282 págs.
}

Reseñar este libro presenta ciertas complicaciones, dada la naturaleza del mismo. Y es que esta publicación no es simplemente una recopilación de trabajos de temática similar, sino que se trata de un ejercicio de interdisciplinariedad, por lo que para hacer una valoración crítica fundamentada se necesitarían conocimientos de un variedad de disciplinas muy diferentes, con objetos de estudio que abarcan desde las instituciones políticas de la Roma Clásica al cómic contemporáneo argentino, pasando por las mentalidades medievales, el paisajismo flamenco o la literatura comparada, entre muchos otros temas. Pero tampoco debe pensarse que el libro es un totum revolutum de trabajos sin coherencia interna. Más bien, como decíamos antes, es la pluralidad de los enfoques, el recurrir a diferentes disciplinas para analizar diversos objetos y realidades sociales; es la reflexión interdisciplinar, en suma, lo que hila los diversos trabajos. Así, el libro puede valorarse positivamente desde tres puntos de vista: por una parte, el de los trabajos individuales, como trabajos de investigación en sus respectivas disciplinas; por otra, para introducirse en la variedad de ciencia sociales y disciplinas humanísticas, cuyas divisiones internas quedan diluidas ante la variedad temática; y finalmente, por el valor propio del libro, que es un llamamiento a utilizar diversidad de enfoques a la hora de analizar los objetos de estudio tradicionalmente asociados a cada disciplina. No es que el volumen esté exento de partes más flojas, como todos los trabajos de estas características, sino que debido al carácter de la propuesta, y a la calidad de gran parte de su contenido, parece más adecuado destacar sus puntos fuertes, sus potencialidades.

Los textos están divididos en cinco apartados: "Historia y lenguaje", "Historia e imagen y discurso", "Arte y lenguaje", "Construcción de imaginarios", y un último apartado, "Reflexión interdisciplinar". Así, como se nos dice en la "Introducción", los autores vinculan "dos de los objetos, metodologías y teorías de estudio propuestas: historia, historia del arte, lengua y literatura" (página 8). Esto no significa que no se puedan integrar otras disciplinas. Sonia Gómez-Jordana Ferary, en "Estrategia argumentativa en un tipo de discurso político: el mensaje de Navidad. Análisis lingüístico del mensaje de Navidad de Nicolas Sarkozy (2008)", recurre a la lingüística, en concreto a la teoría de la argumentación de Oswald Ducrot y J.C. Ascombre. En el último trabajo, "¿Literatura comparada sin comparación? Reflexión interdisciplinar desde una epistemología comparatista", de César Domínguez Prieto, se busca un metacomparación de la Literatura comparada con otras disciplinas "comparatistas", entre las que no se encuentran únicamente ciencias sociales, como puedan ser la Sociología comparada o la Antropología comparada, sino también la Anatomía comparada o la Endocrinología comparada, de manera que "sería de singular importancia para el fortalecimiento metodológico de la Literatura comparada comprobar que sus dilemas son compartidos por otras disciplinas comparatistas, entre ellas las adscriptas a las Ciencias sociales" (página 271). Federico L. Silvestre en "El pintor como narrador. Génesis flamenco del paisajismo intradiegético" aúna historia del arte e historia cultural para describir el paso de un paisajista totalmente descriptivo, que busca completa objetividad en su representación del paisaje, a un paisajismo intradiegético en 
el que el paisajista es también el protagonista del cuadro. Por no hablar del aporte filosófico de Claudio Canaparo, que se comentará más adelante en profundidad.

Con ánimo de transmitir el carácter pluridisciplinar del libro, y evitar caer en un breve resumen de cada uno de los textos, se intentará ahora profundizar en tres de los mismos, intentado destacar como se consigue pasar de un capítulo en el que se analiza la actividad cultural de la Movida madrileña - "Relatos incompletos: a propósito de la ambigua posmodernidad española" - a uno en el que el objeto de estudio es una historieta argentina de marcado carácter político -"Militancia e histori(et)a: Héctor Germán Oesterheld y Montoneros", de Edoardo Balletta -.

Uno de los puntos fuertes del volumen es el trabajo de Israel Sanmartín, "El presente en la Edad Media: historia, imagen y discurso milenaristas" (páginas 61-78), que se presenta como una reflexión epistémica acerca del tiempo, el presente y la historia en el mundo medieval, en relación especialmente al milenarismo con el que se refiere "al apocaliptismo, fin del mundo y fin de la historia, a sabiendas que no son necesariamente sinónimos" (página 62). Se aporta un apartado teórico, en el que nos guía mediante diversas preguntas por los principales puntos epistémicos de su trabajo. Así, aprendemos en que consiste la "historia del presente", la aspiración del autor de estudiar la Edad Media como "un presente que estaría imbricado en un pasado y un futuro determinados", de manera que es posible "trabajar con ese espacio temporal de forma autónoma y así comprender mejor todos los planos del mismo".

El presente medieval sería entonces un espacio temporal poliédrico, de manera que para abordar el tema del milenarismo no se pueden olvidar otros aspectos de la realidad medieval, desde aspectos sociales a mentales. Sanmartín profundiza en cuestiones como el carácter escatológico del pensamiento histórico medieval, la importancia de las imágenes para el estudio del apocaliptismo y el milenarismo. La reflexión final, concluye con una serie de puntos que, de nuevo, trabajan tanto con el fenómeno milenarista, desde un enfoque conceptual, como con ideas de carácter más abstracto sobre la relación entre la reflexión sobre el presente, el conflicto social o las justificaciones interesadas de determinadas realidades sociales e históricas. En relación a esto, y aunque Sanmartín no lo menciona en las conclusiones, cabe destacar el recurso al "año 1000" que debemos entender "no como una fecha sino como un concepto en el que podemos englobar diferentes años mil medievales (año 500, año 800, etc)" (página 70), como una forma de superar paradigmas anquilosados en el ámbito de la historia medieval, en el que se hace quizá demasiado énfasis en el año mil como un punto de ruptura entre dos realidades sociales diferentes.

Dentro del mismo apartado, pero con una temática diferente, Alfonso Pinilla aplica una teoría acerca de las diferentes estrategias discursivas a un tipo de discurso muy particular: un cómic de superhéroes ("Palabra, imagen y poder: los atentados del 11-S a través de un cómic Marvel", páginas 107-124). Resulta especialmente interesante el uso de una fuente poco común para el historiador, una fuente que emplea tanto imagen como narración, y, además, no es el único trabajo que recurre al análisis del cómic en este volumen. Edoardo Balletta también recurre a la historieta, en "Militancia e histori(et)a: Hérctor Germán Oesterheld y Montoneros", aunque destacando las diferentes lecturas del cómic. Sin embargo, Pinilla relaciona el discurso del cómic con la sociedad norteamericana poco después del 11-S. Tras una breve descripción de las siete estrategias discursivas que "el poder/orador utiliza para atraerse la atención, y adhesión de la sociedad/auditorio" (página 19) - y que serían Sublimación, Favor, 
Desviación, Miedo, Culpabilidad, Represión, Expulsión -, el autor aplica dicha teoría, detectando varias de estas estrategias, dirigidas a diferentes públicos. Por ejemplo, la estrategia Desviación, que consiste en llamar la atención sobre una cualidad negativa de un enemigo, para lograr la adhesión del colectivo social, se utiliza al tratar a los radicales islámicos, autores materiales del atentado. Estos son unos locos, cuya locura los cuerdos no pueden anticipar. Así mismo, la estrategia Favor, en la que se califica al público con algún atributo positivo, se emplea también al dirigirse a las comunidades musulmanes más moderadas y tolerantes. Por otra parte, el autor lanza la hipótesis de que el contenido del discurso del cómic se acerca en gran medida a la línea ideológica del Partido Demócrata, ya que se utiliza la Desviación tanto para calificar a los radicales como Bin Laden como a los extremistas conservadores que culpan de la catástrofe a la tolerancia y a los valores no-tradicionales. En suma, el capítulo logra, con éxito, aplicar una teoría de la regulación del conflicto a través del discurso - desarrollada por Antonio Rodríguez de las Heras -, a una fuente poco convencional, realizando análisis de caso que empaca perfectamente con la aspiración interdisciplinar del volumen.

El trabajo de Claudio Canaparo, "El pensamiento del ojo", articula toda una batería de conceptos con los que se pretende establecer una nueva "filosofía del ojo", capaz de interpretar el carácter del conocimiento en el mundo contemporáneo, no sólo desde un punto de vista puramente gnoseológico, sino con potencial para interpretar la articulación del colonialismo en el mundo contemporáneo. No en vano, el texto está extraído de un volumen que forma parte de una serie, La emancipación intelectual, en la que se tratan diferentes aspectos de la articulación espacial del colonialismo.

Darle importancia a lo visual no significa para Canaparo establecer una relación entre ver y creer, algo común en el pensamiento europeo. Para el autor, habría que situar lo visual en su debido contexto, en el que juega un papel fundamental la tecnología. Los fenómenos observados "solo por el ojo desnudo poseen una jerarquía secundaria" de manera que "la realidad de lo físico solo es tal cuando se halla mediada, intervenida, significada por la tecnología, por technological devices" (página 125). Así, en la primera parte del escrito, se articula toda una teoría de lo visual en relación a la tecnología, destacando la naturaleza análoga de las dicotomías saber/conocer y ver/mirar, entre la formas no institucionalizadas del conocimiento y lo visual y los aspectos más formales de los mismos. Tampoco se descarta una aproximación histórica al fenómeno, acuñando el concepto de ojo Galileo, como una nueva forma de lo visual que supera al ojo humano y al ojo artificial. El ojo imaginario u ojo Galileo se refiere a las existencias inalcanzables para la vista humana al desnudo, que se perciben con la ayuda de la tecnología. Cobra importancia, en la articulación del conocimiento de lo contemporáneo, el sentido de lo invisible. De esta forma, los media a través de lo visual, ejercen una forma de dominación, que se plasma en la vida cotidiana moderna, desde la mundialización a la educación, desde el colonialismo a la arquitectura. Canaparo consigue, por lo tanto, la articulación de una teoría de lo visual y su aplicación práctica a la hora de entender los fenómenos del mundo contemporáneo.

Quizás cabe destacar el trabajo de Carlos Barros, "La 'historia mixta' como una historia global", en el que, aunque se da importancia a la interdisciplinariedad, se le da más, al menos en el caso de la historia, a la intradisciplinariedad. Siguiendo, lo expuesto en los puntos IV y V del "Manifiesto de Historia a Debate"1, La "historia mixta"

1 V.V.A.A, "Manifiesto de Historia a Debate", 11 de Septiembre de 2001 (consultado el

23/09/2014) [URL= http://www.h-

debate.com/Spanish/manifiesto/idiomas_manf/manifiesto_had_esp.htm]

ISSN 2174-4289 
vendría a ser un enfoque en el que no se descartaría ningún objeto de estudio histórico, sino que su naturaleza sería precisamente aunar dos o más de entre ellos. Se destaca también el uso de las nuevas tecnologías (algo en lo que se centra también otro trabajo del volumen, "el análisis histórico de las imágenes y los programas informáticos. Algunas consideraciones técnico-metodológicas" de Andrés Bresciano) y, en los últimos aparados, Barros usa sus propias investigaciones como ejemplo de lo que es la "historia mixta". Cabe destacar que, de aceptar el enfoque de la "historia mixta" y su intradisciplinariedad, lo que necesita el historiador, además, es un alto grado de interdisciplinariedad. En cada rama del conocimiento histórico, se emplean diferentes disciplinas, que abarcan desde la economía política a la teoría cultural. Por tanto, si la "historia mixta" consiste en aunar diferentes objetos del estudio histórico - las mentalidades y la estructura social, por ejemplo -, el conocimiento de otras disciplinas se vuelve aún más importante para el historiador.

Del mismo apartado, "Reflexión interdisciplinar", destaca especialmente el trabajo de César Domínguez Prieto, “¿Literatura comparada sin comparación? Reflexión interdisciplinar desde una epistemología comparatista”. Se nos introduce en los problemas epistemológicos que presenta la Literatura comparada en los últimos años, en los que se niega la comparación como elemento fundamental, negando así la propia disciplina. En opinión, sin embargo, de Domínguez, la comparación resulta inherente en la mente humana, de manera que "relegar o negar la comparación como método fundamental de todo disciplina comparatista (incluida la Literatura comparada) debe ser considerado un absurdo epistemológico" (página 265). Lo que resulta especialmente interesante para este volumen, es la reflexión sobre el método comparativo, que tendría tres niveles: predisciplinar, disciplinar y transdisciplinar. Predisciplinar, por una parte, ya que la comparación sería "consustancial" a la mente humana. Disciplinar, en cuanto la comparación se emplea en una disciplina específica, con procedimientos específicos para cada objeto. Y transdisciplinar, es decir, la reflexión sobre la comparación en las disciplinas "comparatistas". Y esto lo que nos interesa, en tanto en cuanto el hilo conductor del libro es la interdisciplinariedad. Una buena cantidad de disciplinas humanísticas tienen como método fundamental la comparación, por lo que "la mutua fecundación de las disciplinas comparatistas habría de redundar sin duda en la refundación de un auténtico interlenguaje comparatista y en una mejor comprensión del papel cognitivo de la comparación" (página 272). En suma, en opinión del autor, las reflexiones epistémicas sobre la Literatura comparada deben de hacerse en comparación a otras disciplinas.

Estamos, por lo tanto, ante un volumen en el que lo primordial es la interdisciplinariedad. La interdisciplinariedad es lo que da coherencia y originalidad. Por otra parte, como ya se ha apuntado, el valor del libro descansa también sobre la calidad de la investigación de los trabajos, y sobre la capacidad introductoria, para aquel que no tenga mucha idea sobre muchas de las disciplinas empleadas (como es el caso de quién escribe esta reseña) que realmente pueden llegar a despertar intereses sobre algunos de los temas tratados. Así, si lo relevante era no "el tema, ni el objeto de estudio en sí mismo, sino el enfoque, la metodología y el intento de diálogo de las diferentes disciplinas" (página 8), el objetivo se cumple plenamente.

Roque Sampedro López

Universidad Rey Juan Carlos

roque.sampedro@gmail.com 
Fecha de recepción: 24 de septiembre de 2014.

Fecha de aceptación: 18 de octubre de 2014.

Publicado: 31 de diciembre de 2014.

Para citar: Roque Sampedro López, "Israel Sanmartín Barros, Patricia Calvo González y Eduardo Rey Tristán (eds.), Historia(s), Imágen(es) y Lenguaje(s) en América Latina y Europa". Santiago de Compostela: Universidade de Santiago de Compostela, Servizo de Publicacións e Intercambio Científico, 2012, 282 págs.”, Historiografias, 8 (juliodiciembre, 2014):

pp. 169-172.

http://www.unizar.es/historiografias/historiografias/numeros/8/sampedro.pdf 